$\mathrm{Rh}$ group when there is a possibility that the infant may be affected with some form of haemolytic disease of the foetus.

5. The early and adequate transfusion (with group $\mathrm{O} \mathrm{Rh}$ negative blood) of infants affected with haemolytic disease of the newborn produces most encouraging results. It is desirable to test the donor's erythrocytes against the mother's serum before transfusion.

\title{
REFERENCES
}

BOORMAN, K. E., DODD, B. E., and MOLLISON, P. L. (1942), Brit. Med. J., 2, 535 and 569. (r943) $a . b$ : to be published.

BURNHAM, L. (I94I) Amer. J. Obstet. Gynec, 42, 389.

DACIE, J. V., and MOLLISÓN, P. L. (1943), Lancet, 1, 550.

DIAMOND, L. K. (1942), New Eng. J. Med.

DIENST, A. (1905), Zbl. Gymak., 29, 353 and $65 \mathrm{I}$

GIMSON, J. (r943), Brit. Med. J., 2, 293.

JAVERT, C. T. (1942), Surg. Gymec. Obstet., 74, I.

LEVINE, P. BURNHAM, L., KATZIN, E. M., and VOGEL, P. (I94I), Am. J. Obstet. Gymec., $42,925$.

LLOYD, T. W. (1943), Brit. Med. J., 1, 132.

MOLLISON, P. L. (I943a), Proc. Roy. Soc. Med., 36, 221.

RAC (r943b), Arch. Dis. Child, In press.

RACE, R. R., and TAYLOR, G. L. (I943), Nature, 152, 300.

$\longrightarrow,-$ CAPPELL, D. F., and MCFARLANE, M. N. (I943), Brit. Med. J., 2, 289

$\overline{\text { VOGEL, }}$, BOORMAN K. E., and DODD B. E. (r943) Nature, $152,563$.

WIENER, A. S. (1942), Arch. Path., 32, 227.

(1942), Amer. J. Civil. Path., 12, 302.

- (1943), Science, 98, 182.

— and PETERS, H. R. (r940), A nn. Int. Med., 13, 2306.

- and WEXLER, I. B. (r943), Amer. J. Clin. Path., 13, 393.

\section{THE MEDICO-LEGAL IMPORTANCE OF THE BLOOD GROUPS}

\author{
By G. ROCHE LYNCH, O.B.E., M.B., B.S., D.P.H., F.R.I.C.
}

(Director of Dept. and Lect. Chem. Path., St. Mary's Hospital, London; Lect. in Forensic Medicine axd. Toxicology, St. Mary's and Westminster Hospätals, London; Senior Official Analyst, Home Office)

The medico-legal importance of the agglutinogen factors of the red blood corpuscles designated $A$ and $B$ ( $O$ indicating absence of these factors), and the agglutinin factors of the serum designated $a$ and $b$ may be divided into two headings.

I. The determination of the presence of one or both of these factors in blood, in secretions and in excretions.

2. The utilisation of these agglutinogen factors together with the agglutinogen factors, $\mathrm{M}$ and $\mathrm{N}$, in the determination of non-paternity.

\section{Blood Stains}

The essence of the examination is to establish the group of the stain upon important exhibits and to compare the result with the group of the blood of the victim, obtained either from post-mortem blood or from articles known to have been stained with the victim's blood, e.g. clothing, or, if alive, from samples of his blood. If permission is granted, and it is usually not granted, a comparison is made with the blood from the accused person. Thus, to quote an example, if the blood upon certain exhibits belongs to group $\mathrm{A}$ and the injured person is group $\mathrm{A}$, then the blood upon the exhibits could have come from him, but of course could have come from any other person of group A. The importance of the findings depends greatly upon the evidence available regarding the significance of the exhibits.

If the accused's blood is available for test and is of group B for example, then an explanation as to how articles amongst the exhibits belonging to the accused, e.g. knife or clothing, are stained with blood of group $A$ is a matter for the court.

The accused is in a dilemma, if asked to give his blood for test; the result may be greatly in the accused's favour if his group is the same as the injured man's, but if different the result will tell against him.

It is not possible to obtain a specimen of blood without consent, for no accused person need in law. provide evidence which may be used against him, but I have known cases where articles known to have been stained with material from the prisoner have been seized by the police, examined, and the results given in evidence. 
It is generally possible to determine: the group of a sample of dried blood provided the stain has been dried reasonably quickly and has been kept in a dry state. In favourable cases the blood group can be determined at least eighteen months after the shedding of the blood. The quantity required is small, but depends upon the nature of the article upon which the blood has been shed. Thus a much smaller quantity is required when the blood is deposited upon some non-absorbent article, e.g. metal or glass, as would be required when upon fabric such as a woollen garment. A drop is much easier to work with than a smear. Very roughly a quantity equivalent to a drop of blood whose diameter is about 2 millimetres is sufficient, but larger quantities are preferable.

It is not proposed to discuss the details of the technique employed which was worked out by the late Dr. F. W. Martley and the writer of this article about twenty years ag. There is nothing original in the method, it is merely the application of well-known principles to a particular purpose.

The method resolves itself into a test for the agglutinins and the agglutinogens present.

\section{Agglutinins.}

The stain is soaked in a minimum quantity of saline at room temperature for some hours, the extract is freed as far as possible from extraneous matter and then mixed with a suspension of $\mathrm{A}$ and of $\mathrm{B}$ cells, any agglutination being noted.

It is noteworthy that whilst in blood stains the agglutinogen factors are stable for an indefinite time, the agglutinins are less stable, consequently a negative result is often observed and is not generally to be relied on.

\section{Agglutinogens.}

The stain is soaked with a minimum quantity of group $\mathrm{O}$ serum whose agglutinins $a$ and $b$ give a high titre with $A$ and $B$ cells.' If the anknown stain is, for exanple, of group $A$, the stain will absorb the $a$ agglutinin, but will leave the $b$ agglutinin unchanged, thus when the $\mathrm{O}$ serum is removed from the stain and freed from extraneous matter, the $a$ agglutinin :when tested for by a suspension of A and B cells, agglutination of the former will either be absent or its titre will be markedly lowered whilst the agglutination of the $\mathbf{B}$ cells is hardly affected. This depends upon the amount of the $A$ factor present in the stain tested and upon the amount of $\mathrm{O}$ serum added. Experience alone is necessary to adjust these matters. In addition, careful controls must be made when the stain is deposited upon absorbent material, as experience has shown that all fabrics absorb some of the $a$ and $b$ agglutimins of the $O$ serum added, so that unless there is a marked difference between the absorption of the fabric and the stain plus the fabric, it is not safe to draw any inferences. So the test is essentially a quantitative one, and care must be taken to ensure that the same size piece of fabric is used in both cases, and that the same volume of $\mathrm{O}$ serum is added to each.

\section{The Secretor factor.}

\section{Stains other than blood}

It has been shown that about 60 per cent of the population contain the agglutinogen factors $\mathrm{A}$ and $\mathrm{B}$, corresponding to those in the red blood.cells, in nearly all secretions and excretions, e.g. urine, tears, saliva, sweat, semen, etc., and in particular the relative concentrations of the agglutinogens are high in saliva and semen. The terms secretor and non-secretor are used to differentiate between the two types of individual.

It is possible to demonstrate the presence of the $A$ and $B$ factors in secretors by an examination of the above-mentioned fluids even when they have become dried upon various articles.

If the examination yields a negative result then the material has come from either a person of group $\mathrm{O}$ or a non-secretor.

The technique for the determination of these agglutinogen factors is similar to that for their determination in blood stains as above. The importance is that, for example, it enables the blood group of an individual in certain cases to be determined from a cigarette stub or from a seminal, stain.

To quote a çase, the name of which is for certain reasons omitted. In a room where a man was found murdèred some cigarette stubs were found. They had all been smoked by a person of group B (secretor). Five persons, including the suspect, were known to have been in the 
room over a period of time when the murder could have been committed. All were given cigarettes to smoke and were examined. Of these only one, namely, the suspect was found to belong to group B (secretor), and the deceased from post mortem blood was found to be of group $\mathrm{O}$.

\section{Non-paternity}

The question of non-paternity arises mainly in those cases where a man is alleged to be the father of a child and he denies responsibility. The test has also been used in cases where it is suspected that children have been accidently mixed in a maternity hospital, possibly in cases of child substitution and alleged false maternity. In petitions for divorce, where parentage is denied by the petitioner, evidence has been given which has been accepted by the court. The test has been in use since I929, and in most countries is now generally accepted.

A Select. Committee of the House of Lords in its enquiry into the Bastardy (Blood Tests) Bill (H.L.) made the following statement in their report: "The Committee are unanimously of opinion, that the qualities of blood underlying blood grouping, and the laws of inheritance governing the transmission of these qualities from parents to children are accepted by such a consensus of scientific opinion throughout the civilised world as to render it desirable in the interests of justice for this knowledge to be applicable to affiliation cases."

Although the test is one which can only benefit the man accused of being the father of the child, it can never cause hardship to the mother, for, following the laws of heredity, if the man in fact be the father, the result of the test will always be non-paternity not established:

The test only assists a limited number of men falsely accused, that is to say in those cases where an exclusion is established, but it will be realised that the result may be such that a man may have those characteristics in his blood which render it possible for him to have been the father, yet it is obvious that any other men possessing these characteristics could, so far as the test is concerned, also be the father. Thus, if the man's blood group is found to be AM, which is such that he could have been the father, every other man of that group, and indeed men of certain other groups depending upon those of the mother and child, could also in theory be the father.

The importance of this is that the test is only of value to the courts when non-paternity is established; when non-paternity is not established the test has no value to the court or to any of the parties concerned in the litigation.

Broadly speaking, when the ABO system is used, about one-sixth only of those men falsely accused can be excluded, and when the ABO and MN systems are used about one-third can be excluded.

The chances of an exclusion being achieved in a falsely accused man varies with his blood group, thus a man of $A B N$ group has a very much greater chance than one of AMN.

For a test to be made it is essential that samples from the alleged father, the mother, and the child be examined, as without all three samples no result can be arrived at.

At the present time the courts have no power to compel the test to be made, the man may desire the test, but the mother may decline. Nevertheless a refusal on her part is likely to be unfavourable to her case.

The test cannot do injury to the parties in any way; all that is required is a few drops of blood from the finger (the heel is more convenient in very young infants). It is important that all parties attend at the same time so that the pathologist is satisfied of their identity

The following tables give the results of matings of various types of blood.

\begin{tabular}{|c|c|c|c|c|c|}
\hline Parents & $\begin{array}{l}\text { Children } \\
\text { Possible }\end{array}$ & $\begin{array}{l}\text { Children } \\
\text { Impossible }\end{array}$ & Parents & $\begin{array}{c}\text { Children } \\
\text { Possible }\end{array}$ & $\begin{array}{l}\text { Children } \\
\text { Impossible }\end{array}$ \\
\hline $\begin{aligned} \mathbf{A B} & \times \mathbf{A B} \\
\mathbf{A B} & \times \mathbf{A} \\
\mathrm{AB} & \times \mathbf{B} \\
\mathrm{AB} & \times \mathbf{O} \\
\mathbf{A} & \times \mathbf{A}\end{aligned}$ & $\begin{array}{c}\mathrm{AB}, \mathrm{A}, \mathrm{B} \\
\mathrm{AB}, \mathrm{A}, \mathrm{B} \\
\mathrm{AB}, \mathrm{A}, \mathrm{B} \\
\mathrm{A}, \mathrm{B} \\
\mathrm{A}, \mathrm{O}\end{array}$ & $\begin{array}{c}\mathrm{O} \\
\mathrm{O} \\
\mathrm{O} \\
\mathrm{AB}, \mathrm{O} \\
\mathrm{AB}, \mathrm{B}\end{array}$ & $\begin{array}{l}A \times B \\
A \times O \\
B \times B \\
B \times O \\
O \times O\end{array}$ & $\begin{array}{c}\text { AB, A, B, O } \\
\text { A, O } \\
\text { B, O } \\
\text { B, O } \\
\text { O }\end{array}$ & $\begin{array}{c}\overline{A B}, \mathrm{~B} \\
\mathrm{AB}, \mathrm{A} \\
\mathrm{AB}, \mathrm{A} \\
\mathrm{AB}, \mathrm{A}, \mathrm{B}\end{array}$ \\
\hline
\end{tabular}




\begin{tabular}{|c|c|c|c|c|c|}
\hline Parents & $\begin{array}{c}\text { Children } \\
\text { Possitile }\end{array}$ & $\begin{array}{l}\text { Children } \\
\text { Impossible }\end{array}$ & Parents & $\begin{array}{c}\text { Children } \\
\text { Possible }\end{array}$ & $\begin{array}{l}\text { Children } \\
\text { Impossible }\end{array}$ \\
\hline $\begin{array}{l}\mathrm{M} \times \mathbf{M} \\
\mathrm{M} \times \mathrm{MN} \\
\mathrm{M} \times \mathrm{N}\end{array}$ & 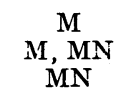 & $\underset{M, N}{M N, N}$ & $\begin{aligned} \mathrm{MN} & \times \mathrm{MN} \\
\mathrm{MN} & \times \mathrm{N} \\
\mathbf{N} & \times \mathbf{N}\end{aligned}$ & $\underset{\mathbf{N}}{\mathrm{M}, \mathrm{MN}} \underset{\mathbf{M N}}{\mathbf{N}}$ & $\overline{M N}_{\mathrm{MN}, \mathrm{M}}$ \\
\hline
\end{tabular}

From these tables there follow two laws for each agglutinogen system.

ABO SYSTEM.

I. The agglutinogens $\mathrm{A}$ and $\mathrm{B}$ cannot appear in the blood of a child unless present in the blood of one or both parents.

2. A group $O$ parent cannot have a group $A B$ child, and an $A B$ parent cannot have an $\mathrm{O}$ child.

\section{MN SYSTEM.}

I. The agglutinogens $\mathrm{M}$ and $\mathrm{N}$ cannot appear in the blood of a child unless present in the blood of one or both parents. $\mathrm{M}$ child.

2. A type $\mathrm{M}$. parent cannot have a type $\mathrm{N}$ child, and an $\mathrm{N}$ parent cannot have an

Although it is generally possible to establish the blood group of a newly-born infant, occasionally it may happen that the result is not sufficiently conclusive to justify a final report. In such cases the pathologist will realise the position and arrange for a second test later. Generally speaking, it is preferable to wait until the child is at least two months old before the test is made.

\section{Other Blood Factors.}

As has been stated, only roughly one-third of men falsely accused can at the present time be excluded, consequently if any other blood factors can be shown to obey Mendelian laws the percentage exclusions can be increased. Probably in the future use will be made of the sub-groups of $\mathrm{A}$ and possibly of $\mathrm{N}$.

The secretor factor referred to in the examination of stains other than blood may possibly be of assistance, as it is now believed that the secretor property is a Mendelian dominant.

\section{The Technique of the Test}

The determination of the blood group in the ABO series is carried out in the same manner as is used in blood transfusion, but in view of the issues the agglutinins present should always be determined.

The fundamental difference between the $\mathrm{ABO}$ and $\mathrm{MN}$ systems is that in the latter the human blood contains no agglutinins $m$ and $n$. These are prepared by injecting rabbits with human blood cells of group OM and ON. When,a satisfactory titre is obtained the rabbit sera are absorbed with $A, B$, and $O$ cells of type $M$ for the rabbit anti-N serum, and $A, B$, and $O$ cells of type. $\mathrm{N}$ for the anti-M serum. Careful controls for potence and specificity should be done at frequent intervals.

\section{BRITISH ASSOCIATION OF OTOLARYNGOLOGISTS}

The above Association has been formed; the officers are as follows:-

$$
\begin{aligned}
& \text { President - - - W. M. MOLLISON, C.B.E., M.CH. } \\
& \text { Vice-President - } \\
& \text { Honorary Treasurer } \\
& \text { Honorary Secretary }
\end{aligned}
$$

